$\mathbb{P}$ periodica polytechnica

Chemical Engineering

57/1-2 (2013) 21, 24

doi: $10.3311 /$ PPch.2166

http://periodicapolytechnica.org/ch

Creative Commons Attribution (i)

RESEARCH ARTICLE

\section{Treatment of model oily waste water by microfiltration}

\author{
Zsolt László Kiss / László Talpas / Zita Seres / Sándor Beszédes / Cecília Hodúr / \\ Zsuzsanna László
}

Received 2012-12-20, accepted 2013-04-24

\begin{abstract}
Microfiltration membranes made from polytetrafluorethylene (PTFE) have been successfully used for the separation of oily waste waters by membrane coalescence, but filtration of the oily waste waters with high emulsifier content have not yet been investigated. Our aim was to examine the effect of emulsifier content on membrane coalescence on this type of membrane, and to investigate the effect of surfactant addition on oil retention and filtration parameters. It was found that the oil content of the emulsion can be separated with MF PTFE membranes. Efficiency of the retention depends on the concentration of emulsion: increasing concentrations resulted in an increased retention. The addition of coagulant also affected filtration parameters: higher coagulant concentrations resulted in a significant increase of the flux, while the retention marginally decreased.
\end{abstract}

\section{Keywords}

microfiltration - hydrophobic membrane $\cdot$ water miscible oil emulsion

\section{Acknowledgement}

The authors are grateful for the financial support provided by the project IPA Cross-border cooperation program (SerbiaHungary) HUSRB 1203/221/196 and the project TÁMOP4.2.1/B-09/1/KONV-2010-005 supported by the European Union and co-financed by the European Regional Fund.

\section{Zsolt László Kiss}

László Talpas

University of Szeged, Faculty of Engineering, Moszkvai str, 9., Szeged, H-6725, Hungary

\section{Zita Seres}

Faculty of Technology, University of Novi Sad, Bu. Cara Lazara 1., Novi Sad, SRB-21000, Serbia

\section{Sándor Beszédes}

Cecília Hodúr

Zsuzsanna László

University of Szeged, Faculty of Engineering, Moszkvai str, 9., Szeged, H-6725, Hungary

\section{Introduction}

Oil in water emulsions of waste waters are produced by industries such as the food industry, and metal-working [1,2]. However, they cannot be discharged to the sewer because of a high oil content and high residual organic pollution [3]. Hence, they have to be treated in order to obtain a concentrated as possible oily phase so that the oil and aqueous phase can be reused in accordance with the regulation levels for industrial wastewater. However, the conventional methods used for the treatment of oil emulsions have several disadvantages, such as a low efficiency, operational difficulties and high operation costs [4 5]. The problem becomes more pronounced when surfactants are present in waste water, as these enhance the oily emulsion stability [6]. Several studies have reported on the use of membrane filtration for the treatment of oil; however most studies focused on the use of ultrafiltration (UF) and microfiltration (MF) [7]-[10]. Only a few studies have been performed on the membrane filtration of high emulsifier-containing oil-in-water (o/w) emulsions. Earlier studies [4, 11, 12] found that a stable $\mathrm{o} / \mathrm{w}$ emulsion (the water miscible cutting oil concentration in the emulsion was $5 \mathrm{wt} . \%$ ) could be separated by cross-flow UF, and that the mixing has a determinant role: the use of a static mixer led to a considerable increase in the permeate flux.

Microfiltration membranes successfully made from polytetrafluorethylene (PTFE) were used for the separation of oily waste waters by membrane coalescence [6]-[13]. Membrane surface chemistry, membrane-solute and solute-solute interactions determine the flux and the retention of oil and are the key to understanding fouling phenomena. During filtration, the oil droplets accumulate at the surface of the membrane, and the concentration of the oil may be much higher than in bulk solution. If the concentration exceeds the critical micelle concentration (cmc), larger micelles form, which enhances the retention [14]. The addition of surfactants may change the wettability of hydrophobic surfaces, like membranes [15], enhancing the separation efficiency of microfiltration; on the other hand, this may destabilise the oily emulsions, increasing membrane coalescence [16].

The aim of the present work was to investigate the microfil- 
tration of a high emulsifier-containing o/w emulsion by PTFE membrane oil-in-water emulsion using a PTFE microfiltration membrane, and to investigate the effect of surfactant addition on oil retention and filtration parameters.

\section{Methods}

\section{Microfiltration of oily model solutions}

Materials: Model solutions were prepared from watermiscible stable oil emulsion (MOL Makromil 200) (Table 1 (denoted WMO), at concentrations of $0.1,1.0$ and $3.0 \mathrm{wt} . \%$, and a conventional petroleum motor-oil (AGIP 15W-50) (denoted NWMO) at a concentration of $3.0 \mathrm{wt}$.\%. BOPAC solutions were made from BOPAC-S (polyaluminium-chloride), (Unichem Kft, Kistelek, Hungary). Flat-sheet PTFE membranes $(0.1 \mu \mathrm{m})$ on PE series (New Logic, USA) were used. The membrane effective area was $0.001734 \mathrm{~m}^{2}$.

Tab. 1. MOL Makromil 200 motor-oil content

\begin{tabular}{lr}
\hline Content & $\begin{array}{r}\text { Concentration } \\
\text { (wt\%) }\end{array}$ \\
\hline Petroleum motor oil $\left(\mathrm{C}_{24}-\mathrm{C}_{50}\right)$ & Max. 62 \\
Tetrapropylene succinic acid monobotyl ester & Max. 6.3 \\
2-hydroxyethyl oleate & Max. 12.3 \\
Sodium sulphonate & Max. 4.4 \\
Alcohols, $\mathrm{C}_{12}-\mathrm{C}_{16}>98 \%$ & Max. 6.8 \\
2,2',2"-(Hexahydro-1,3,5-triazin-1,3,5-triyl) triethanol & Max. 2.0 \\
\hline
\end{tabular}

\section{Experimental design}

The MF experiments were carried out in batch stirred cell (Millipore, Serial No94) with a capacity of $50 \mathrm{~cm}^{3}$. Before MF experiments, the membrane was conditioned with a $1 \%$ concentration of isopropyl-alcohol followed by 0.5 hour conditioning with distilled water. The initial feed volume was $50 \mathrm{~cm}^{3}$. The MF experiments were carried out at $0.1 \mathrm{MPa}$, until $10 \mathrm{~cm}^{3}$ of the total sample was filtered.

\section{Analytical methods}

The measured parameter was the chemical oxygen demand (COD) retention. Determination of the COD was based on the standard method involving potassium-dichromate oxidation; for the analysis, standard test tubes (Lovibond, Tintometer $\mathrm{GmbH}$, Germany) were used. The digestions were carried out in a COD digester (Lovibond, ET 108, Tintometer GmbH, Germany), and the COD values were measured with a COD photometer (Lovibond PC-CheckIt, Tintometer GmbH, Germany). The conductivity was measured by a multiparameter analyser (Consort C535, Belgium).

In order to investigate the membrane fouling, the different fouling resistances were calculated on the basis of the resistances in series model. The rate and extent of membrane fouling and its effect on flux for any given system depends on various parameters, such as the specific interactions between the membrane surface and various fouling species, hydrodynamic forces exerted by the flowing fluid and process parameters such as the cross-flow velocity, TMP, feed concentration, pore size and temperature.

The membrane resistance was calculated as:

$$
R_{\mathrm{M}}=\frac{\Delta p}{J_{\mathrm{w}} \eta_{\mathrm{w}}} \quad\left[m^{-1}\right]
$$

where $R_{\mathrm{M}}$ is the membrane resistance, $\Delta p$ is the pressure difference between the two sides of the membrane [MPa], $J_{\mathrm{W}}$ is the water flux of the clean membrane and $\eta_{\mathrm{W}}$ is the water viscosity [Pas].

$R_{\mathrm{T}}$ is the total resistance $\left[\mathrm{m}^{-1}\right]$, which can be evaluated from the steady-state flux by using the resistance-in-series model:

$$
R_{\text {Total }}=R_{\mathrm{M}}+R_{\mathrm{F}}+R_{\mathrm{P}} \quad\left[m^{-1}\right]
$$

where $R_{\mathrm{F}}$ is the fouling resistance (mainly by the fouled pores) $\left[\mathrm{m}^{-1}\right]$ and $R_{\mathrm{P}}$ is the polarisation layer resistance $\left[\mathrm{m}^{-1}\right]$.

The resistance of the fouling was determined by measuring water flux through the membrane after filtration and rinsing it with deionised water to remove any particles of residue layer from the surface, by subtracting the resistance of the clean membrane:

$$
R_{\mathrm{F}}=\frac{\Delta p}{J_{\mathrm{WA}} \eta_{\mathrm{W}}}-R_{\mathrm{M}} \quad\left[m^{-1}\right]
$$

where $J_{\mathrm{WA}}$ is the water flux after concentration tests. The resistance of the polarisation layer can be calculated as:

$$
R_{\mathrm{P}}=\frac{\Delta p}{J_{\mathrm{C}} \eta_{\mathrm{WW}}}-R_{\mathrm{F}}-R_{\mathrm{M}} \quad\left[m^{-1}\right]
$$

where $J_{C}$ is the constant flux at the end of the concentration and $\eta_{\mathrm{WW}}$ is the wastewater viscosity. [17]

\subsection{Determination of CMC}

The cmc values were determined conductometrically [18] using a multiparameter analyser (Consort C535). The conductivity of these solutions was measured at $293 \mathrm{~K}$.

\section{Results and discussion}

\section{Conditioning the PTFE membrane}

In the first series of experiments, the conditioning of the hydrophobic PTFE membrane was investigated in order to make it useable for the filtration of water-based solutions. The conditioning was carried out in a $1 \%$ concentration of isopropylalcohol for $30 \mathrm{~min}$ by increasing the transmembrane pressure (TMP); then, the membrane was conditioned for $30 \mathrm{~min}$ in distilled water. It was found that this is an appropriate method for wetting the hydrophobic membrane surface.

\section{Comparison of filterability of WMO and NWMO-containing model waste waters}

Relative permeate fluxes $\left(\mathrm{J} / \mathrm{J}_{\mathrm{w}}\right)$ show the flux decline during filtration versus flux of the solvent (distilled water in this case). The flux of distilled water was $47.18 \pm 3.01 \mathrm{~L} \cdot \mathrm{m}^{-2} \mathrm{~h}^{-1}$ at 0.1 MPa TMP. Relative fluxes of $3 \%$ emulsions in the function of 


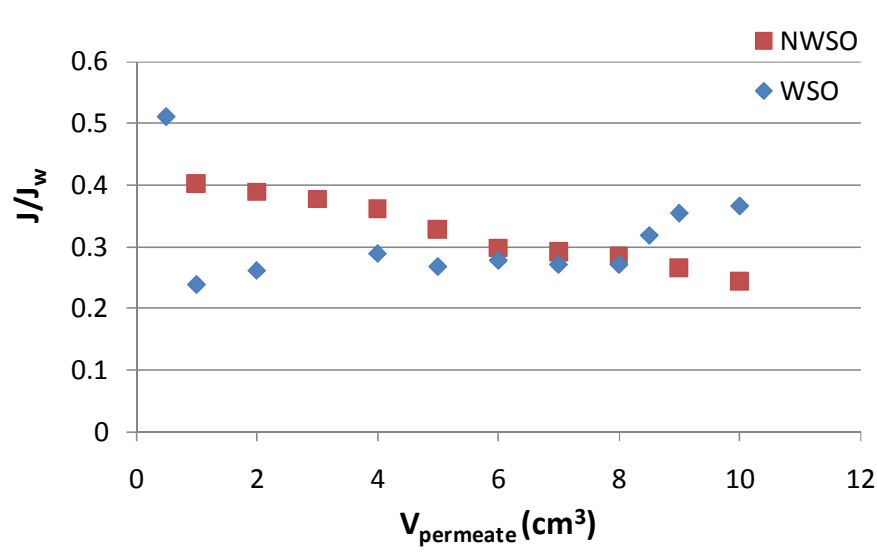

Fig. 1. Relative permeate flux as a function of permeate volumes of different kinds of emulsions.

permeate volume are shown in Fig. 1. In the case of WMO, the relative permeate flux decreases in the first part of the batch, but in the second part of the batch it increases. This surprising result can be explained by interaction between the surfactant components of emulsion and the membrane surface. In the case of NWMO emulsion, a decrease of the relative permeates flux was smooth, as expected. The average retention values show (Fig.2) that higher retention values can be achieved in the case of nonwater-miscible oil emulsion due to membrane coalescence and phase separation during filtration.

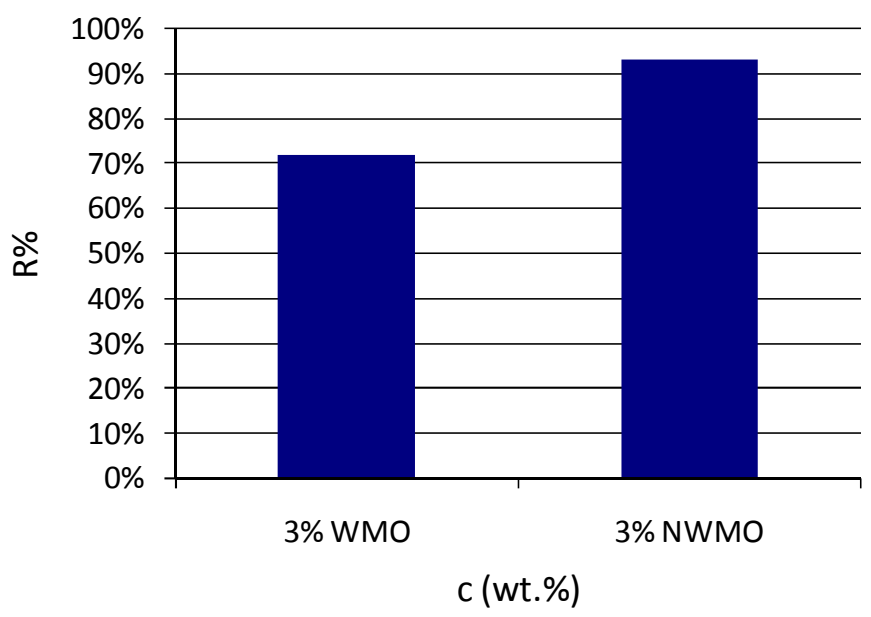

Fig. 2. Retention values of $3 \% \mathrm{WMO}$ and $3 \%$ NWMO containing model waste waters

\section{Effect of oil concentration on filtration parameters}

In the next series of experiments, different concentrations of WMO emulsion were filtered. The resistances were calculated according to the resistances in series model (Eq. 1 4). It was found that the decline of the fluxes was caused by building of the polarisation layer, while the effect of fouling on flux decreases was negligible. The average permeate flux and the polarisation layer resistance values are shown in Fig. 4. The flux is reciprocally proportional to polarisation resistance, revealing the effect of the polarisation layer on flux decline. On the other hand, the flux decline and polarisation resistance is not proportional to oil

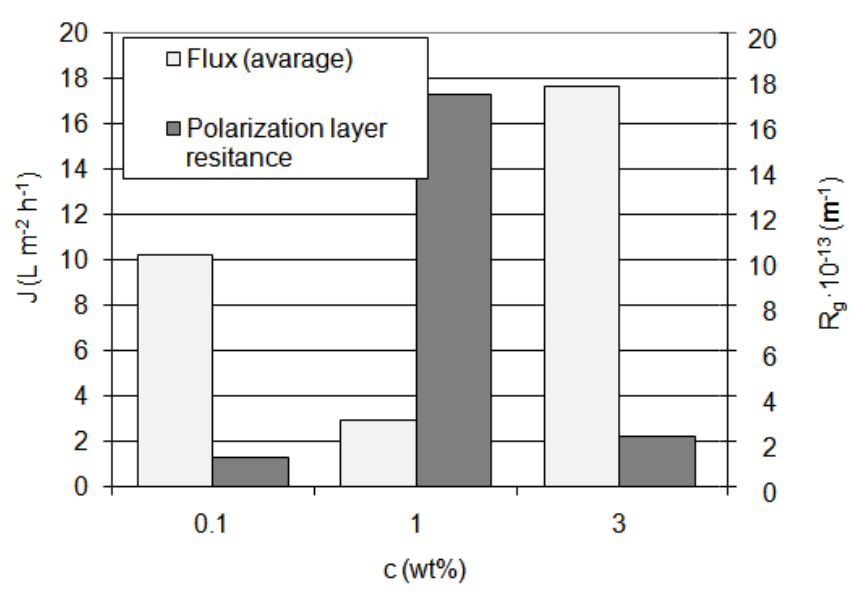

Fig. 3. Average permeate flux and polarisation layer resistances of model waste waters with different WMO concentrations during MF

concentration. This can probably be explained by oil concentration in the polarisation layer. In the case of 0.1 and $1 \%$ oil emulsions, the oil concentration does not exceed the $\mathrm{cmc}$, and the resistance is higher at higher concentrations. In the case of $3 \%$ emulsion, the oil concentration on the gel layer may exceed the $12.16 \% \mathrm{cmc}$, causing a change in the structure of the gel layer, resulting in higher permeate fluxes and lower polarisation resistance.

\section{Effect of coagulant on microfiltration of WMO emulsions}

In order to investigate the effect of coagulant on oil retention and filtration parameters, BOPAC concentration was set to $0.5 \%$ and $0.3 \%$ in waste water solution. It was found that higher concentrations of coagulant resulted in higher relative permeate fluxes (Fig. 4). This can be explained by the coagulant effect of BOPAC, which breaks the stable oil emulsion, changing the compact structure of the polarisation layer.

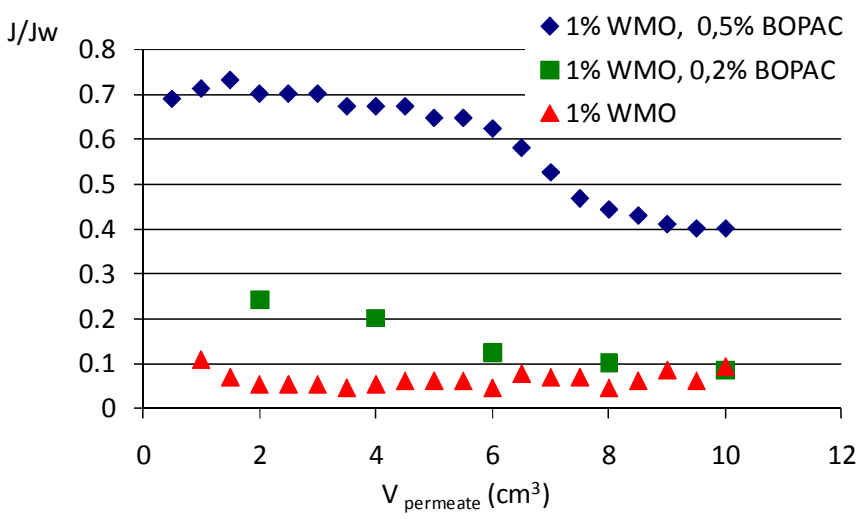

Fig. 4. Relative permeate fluxes at different concentrations of coagulant and $1 \% \mathrm{WMO}$ emulsions

\section{Retention values during MF}

When calculating the retention of the organic content of the emulsion (expressed by COD), it was found that the retention increased with increasing concentrations of emulsion (Fig. 5). This probably can be explained by the interactions between the 
membrane and surfactant content of the solution; in higher concentrations of WMO (containing higher concentrations of surfactants) the membrane became less hydrophobic, improving oil retention. It also can be noted that the conductivity of the permeate is relatively high (retention expressed with conductivity is only $32 \%$ ), since the polymerised aluminium chloride solutions contains monomers too, which can pass through the membrane [19].

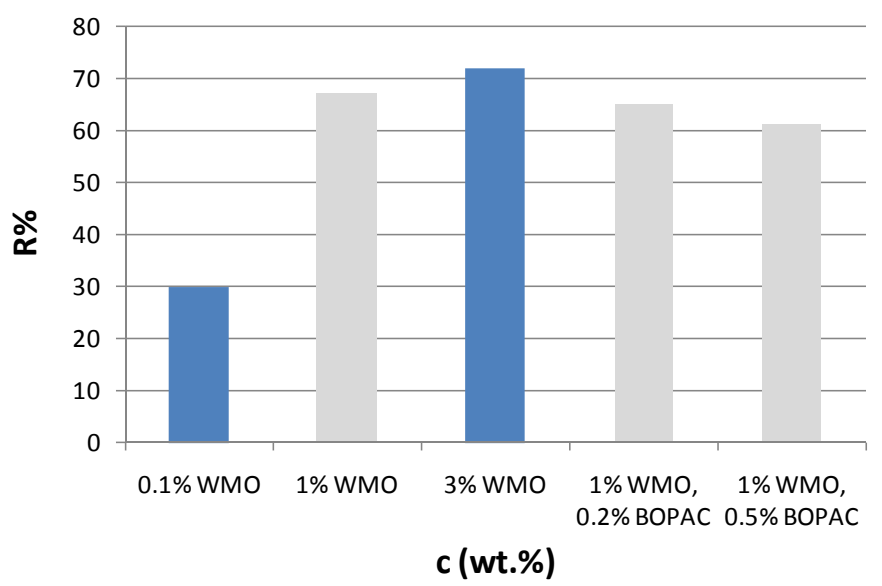

Fig. 5. Retention values of WMO emulsions

\section{Conclusions}

Recent work has been aimed at the investigation of microfiltration of water-miscible oil emulsion by hydrophobic PTFE membrane. From the experimental results (flux- and retention values) it was found that the oil content of the emulsion can be separated with an MF PTFE membrane, but the presence of emulsifiers decreases the retention due to the arrest of oil coalescence. The efficiency of the retention depends on the concentration of emulsion; higher emulsifier contents considerably change the affect on membrane-solution interactions, increasing oil retention. The addition of coagulant also affected filtration parameters, with higher coagulant concentrations resulting in a significant increase of the flux, due to destabilisation of the stable oil emulsion.

\section{References}

1 Abbasi M, Mirfendereski M, Nikbakht M, Golshenas M, Mohammadi $\mathbf{T}$, Performance study of mullite and mullite-alumina ceramic MF membranes for oily wastewaters treatment, Desalination, 259, (2010), 169-178.

2 Zhou YB, Tang XY, Hu XM, Fritschi S, Lu J, Emulsified oily wastewater treatment using a hybrid-modified resin and activated carbon system, Separation and Purification Technology, 63, (2008), 1400-406.

3 Li YS, Yan L, Xiang CB, Hong LJ, Treatment of oily wastewater by organic-inorganic composite tubular ultrafiltration (UF) membranes, Desalination, 196, (2006), 76-83.

4 Krstić DM, Hoflinger W, Koris AK, Vatai GN, Energy-saving potential of cross-flow ultrafiltration with inserted static mixer: Application to an oil-inwater emulsion, Separation and Purification Technology, 57, (2007), 134139.

5 Yan L, Honga S, Li ML, Li YS, Application of the $\mathrm{Al}_{2} \mathrm{O}_{3}-P V D F$ nanocomposite tubular ultrafiltration (UF) membrane for oily wastewater treatment and its antifouling research, Separation and Purification Technology, 66, (2009), 347-352.

6 Hong A, Fane AG, Buford R, Factors affecting membrane coalescence of stable oil-in-water emulsions, Journal of Membrane Science, 222, (2003), 19-39.

7 Salahi A, Abbasi M, Mohammadi T, Permeate flux decline during UF of oily wastewater: Experimental and modelling, Desalination, 251, (2010), 153-160.

8 Salahi A, Gheshlaghi A, Mohammadi T, Madaeni SS, Experimental performance evaluation of polymeric membranes for treatment of an industrial oily wastewater, Desalination, 262, (2010), 235-242.

9 Kertész S, Erbasi E., László Z, Hovorka-Horváth Z, Szabó G, Hodúr C, Oily wastewaters separation by ultrafiltration, IWA Regional Conference and Exhibition, In: Membrane Technology \& Water Reuse, 2010, pp. 351355.

10 Nazzal FF, Wiesner MR, Microfiltration of oil-in-water emulsion, Water Environment Research, 68, (1996), 1187-1191.

11 Vatai GN, Krstic DM, Höflinger WH, Koris AK, Tekic MN, Combining air sparging and the use of a static mixer in cross-flow ultrafiltration of oil/water emulsion, Desalination, 204, (2007), 255-264.

12 Koris A, Piacettini E, Vatai G, Békássy-Molnár E, Drioli E, Giorno L, Investigation on the effects of a mechanical shear-stress modification method during cross-flow membrane emulsification, Journal of Membrane Science, 371, (2011), 28-36.

13 Hong AC, Fane AG, Burford RP, The effects of intermittent permeate flow and crossflow on membrane coalescence of oil in water emulsions, Desalination, 144, (2002), 185-191.

14 Nguyen LAT, Minding M, Schwarze M, Drews A, Schomäcker R, Kraume M, Adsorption and filtration behaviour of non-ionic surfactants during reverse micellar-enhanced ultrafiltration, Journal of Membrane Science, 433, (2013), 80-87.

15 Ferrari M, Ravera F, Surfactants and wetting at superhydrophobic surfaces: Water solutions and non aqueous liquids, Advances in Colloid and Interface Science, 161, (2010), 22-28.

16 Gunesa DZ, Claina X, Bretona O, Mayora G, Burbidge AS, Avalanches of coalescence events and local extensional flows - Stabilisation or destabilisation due to surfactant, Journal of Colloid and Interface Science, 343(1), (2010), 78-86.

17 Kertész S, László Z, Forgács E, Szabó G, Hodúr C, Dairy wastewater purification by vibratory shear enhanced processing, Desalination and Water Treatment, 37, (2012), 1-7.

18 Santhakumar K, Kumaraguru N, Arumugham MN, Arunachalam S, Metallomicelles of Co(III) coordination complexes - Synthesis, characterisation and determination of CMC values, Polyhedron, 25, (2006), 1507-1513.

19 Boa J, Polialumínium-klorid, az ígéretes koaguláns, 2006, http://www. vinyl.hu/doc/Polialuminium_klorid.pdf 